\title{
TEM Study of Mn-Doped ZnO Thin Films Synthesized by PLD
}

\author{
X. Z. Li, Jun Zhang, ${ }^{* * *}$ and D. J. Sellmyer ${ }^{* * *}$ \\ * Center for Materials Research and Analysis, University of Nebraska, Lincoln, NE 68588 \\ ** Department of Physics and Astronomy, University of Nebraska, Lincoln, NE 68588
}

The prediction of high-temperature ferromagnetism (FM) in ZnO-based diluted magnetic semiconductors has stimulated considerable research [1,2]. Both the existence and absence of FM have been reported in $\mathrm{Mn}$-doped $\mathrm{ZnO}$ thin films. The recently observed FM in $\mathrm{Mn}-\mathrm{Zn}-\mathrm{O}$ bulk materials synthesized at a low-temperature of $500{ }^{\circ} \mathrm{C}$ has been argued to arise from the presence of modified $\mathrm{Mn}$ oxides, instead of intrinsically from $\mathrm{ZnO}$ with $\mathrm{Mn}$ substituting for $\mathrm{Zn} \mathrm{[3].} \mathrm{The}$ solubility of $\mathrm{Mn}$ in the low-temperature synthesized bulk $\mathrm{ZnO}$ is very low, and $\mathrm{Mn}$ oxides exist with as little as only $1 \% \mathrm{Mn}$ doping [4]. It is believed that $\mathrm{Mn}$ has higher solubility in $\mathrm{ZnO}$ thin films grown by pulsed laser deposition (PLD). In this paper, we report a TEM study of the structure of Mn-doped $\mathrm{ZnO}$ thin films grown by PLD, with special attention given to examining the possible existence of manganese oxides or other impurity phases.

A series of samples, $\mathrm{Zn}_{1-\mathrm{x}} \mathrm{Mn}_{\mathrm{x}} \mathrm{O}$ with $\mathrm{x}=0,0.01,0.03$ and 0.05 , have been synthesized and studied. Magnetization was measured using a superconducting quantum interference device (SQUID) magnetometer (Quantum Design, MPMS-XL) at room temperature as a function of the applied magnetic field. Fig. 1 shows the field dependence of magnetization curves of $\mathrm{Zn}_{1-\mathrm{x}} \mathrm{Mn}_{\mathrm{x}} \mathrm{O}$ thin films with $\mathrm{x}=0.01,0.03$, and 0.05 at $300 \mathrm{~K}$. The magnetization curves show hysteresis, with remanences and the coercivities very similar to the previous reported result [5], suggesting existence of ferromagnetic ordering at room temperature. Details of the synthesis and magnetic properties of the $\mathrm{Mn}$-doped $\mathrm{ZnO}$ thin films will be reported elsewhere.

The film structures were studied by using TEM (Jeol JEM-2010, 200kV). Figure 2 shows the SAED patterns. The undoped and Mn-doped $\mathrm{ZnO}$ films show a preferred (001) orientation. As $\mathrm{Mn}$ concentration increases up to $3 \%$, the $(001)$ orientation deteriorates in some area of the films. No manganese oxides have been detected for samples, $\mathrm{Zn}_{1-\mathrm{x}} \mathrm{Mn}_{\mathrm{x}} \mathrm{O}$ with $\mathrm{x}=0.01$ and 0.03 and a weak disconnected ring of the $\mathrm{Mn}_{2} \mathrm{O}_{3}$ (211) was observed in sample $\mathrm{Zn}_{1-\mathrm{x}} \mathrm{Mn}_{\mathrm{x}} \mathrm{O}$ with $\mathrm{x}=0.05$. The films were also studied by X-ray diffractometer (Riguka, D/Max-B, $\mathrm{Cu} \mathrm{K} \alpha, \lambda=0.154 \mathrm{~nm}$ ) and the $\mathrm{ZnO}$ (002) and (004) peaks are observed shifting slightly to lower angle as Mn concentration increases; however, the $\mathrm{Mn}_{2} \mathrm{O}_{3}$ phase was not detected in X-ray diffraction diagrams. HREM images were taken for further study to detect if there exist $\mathrm{Mn}$ oxides in the $\mathrm{Zn}_{1-\mathrm{x}} \mathrm{Mn}_{\mathrm{x}} \mathrm{O}$ films with $\mathrm{x}=0.01$ (and $\mathrm{x}=0.0$ for comparison). Figure 3 is a HREM image of a $\mathrm{Zn}_{1-\mathrm{x}} \mathrm{Mn}_{\mathrm{x}} \mathrm{O}$ thin film $(\mathrm{x}=0.01)$ with incident beam parallel to the normal of the film, which shows clean and sharp grain boundaries. In the enlarged image of a selected area, hexagonal arrangements of spots are clearly visible throughout the entire image, consistent with the hexagonal $\mathrm{ZnO}$ structure. No secondary phase aggregations are found in the grains and the grain boundaries.

In summary, TEM study of $\mathrm{Zn}_{1-\mathrm{x}} \mathrm{Mn}_{\mathrm{x}} \mathrm{O}$ thin films with $\mathrm{x}=0,0.01,0.03$ and 0.05 synthesized by PLD shows that $\mathrm{Mn}$ oxides or other impurity phases were not present in the $\mathrm{Zn}_{1-\mathrm{x}} \mathrm{Mn}_{\mathrm{x}} \mathrm{O}$ thin films for $\mathrm{x} \leq 0.03$. Thus ferromagnetism observed at room temperature in the $\mathrm{ZnO}$ thin films lightly doped $\mathrm{Mn}$ is not related to nanometer scale manganese oxides or other impurity phases. 


\section{References}

[1] T. Dietl, H. Ohno, F. Matsukura, J. Cibert, and D. Ferrand, Science 287 (2000) 1019.

[2] K. Sato, and H. Katayama-Yoshida, Jpn. J. Appl. Phys., Part 239 (2000) L555.

[3] D. Kundaliya, S. Ogale, S. Lofland, S. Dhar, C. Metting, S. Shinde, Z. Ma, B. Varughese,

K. Ramanujachary, L. Salamanca-Riba, and T. Venkatesan, Nature Mater. 3 (2004) 709.

[4] Jun Zhang, R. Skomski, and D. J. Sellmyer, J. Appl. Phys. 97 (2005) 10D303.

[5] Y. W. Heo, M. P. Ivill, K. Ip, D. P. Norton, S. J. Pearton, J. G. Kelly, R. Rairigh, A. F. Hebard, and T. Steiner, Appl. Phys. Lett. 84 (2004) 2292.

[6] This work was supported by NSF-MRSEC, W. M. Keck Foundation, NRI and CMRA.
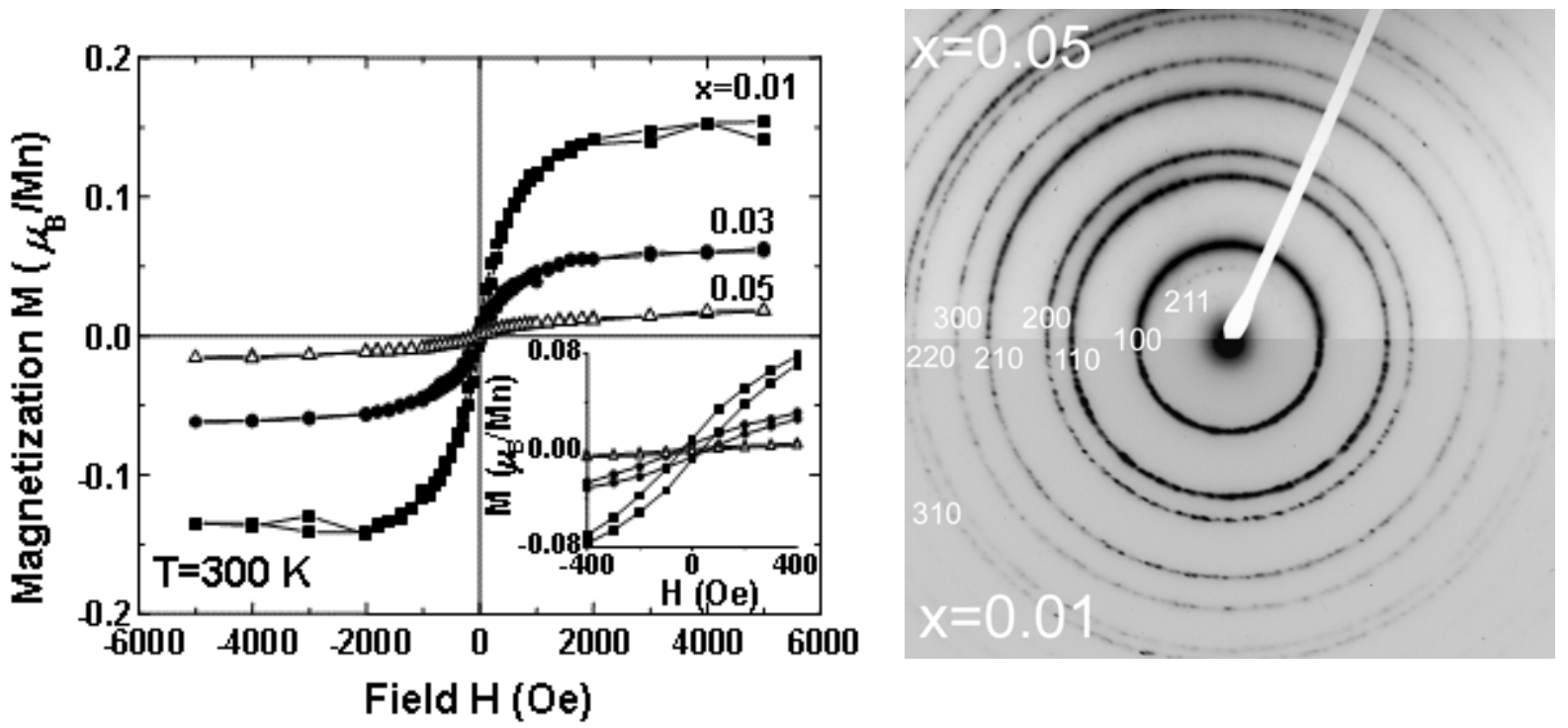

Figure 1 Magnetization curves of $\mathrm{Zn}_{1-\mathrm{x}} \mathrm{Mn}_{\mathrm{x}} \mathrm{O}$ thin films at $300 \mathrm{~K}$; the diamagnetic contribution from the $\mathrm{Si}$ substrate was subtracted. The insert shows the low-field data.

Figure 2 SAED patterns of $\mathrm{Zn}_{1-\mathrm{x}} \mathrm{Mn}_{\mathrm{x}} \mathrm{O}$ thin films with $\mathrm{x}=0.01$ (lower) and $\mathrm{x}=0.05$ (upper).
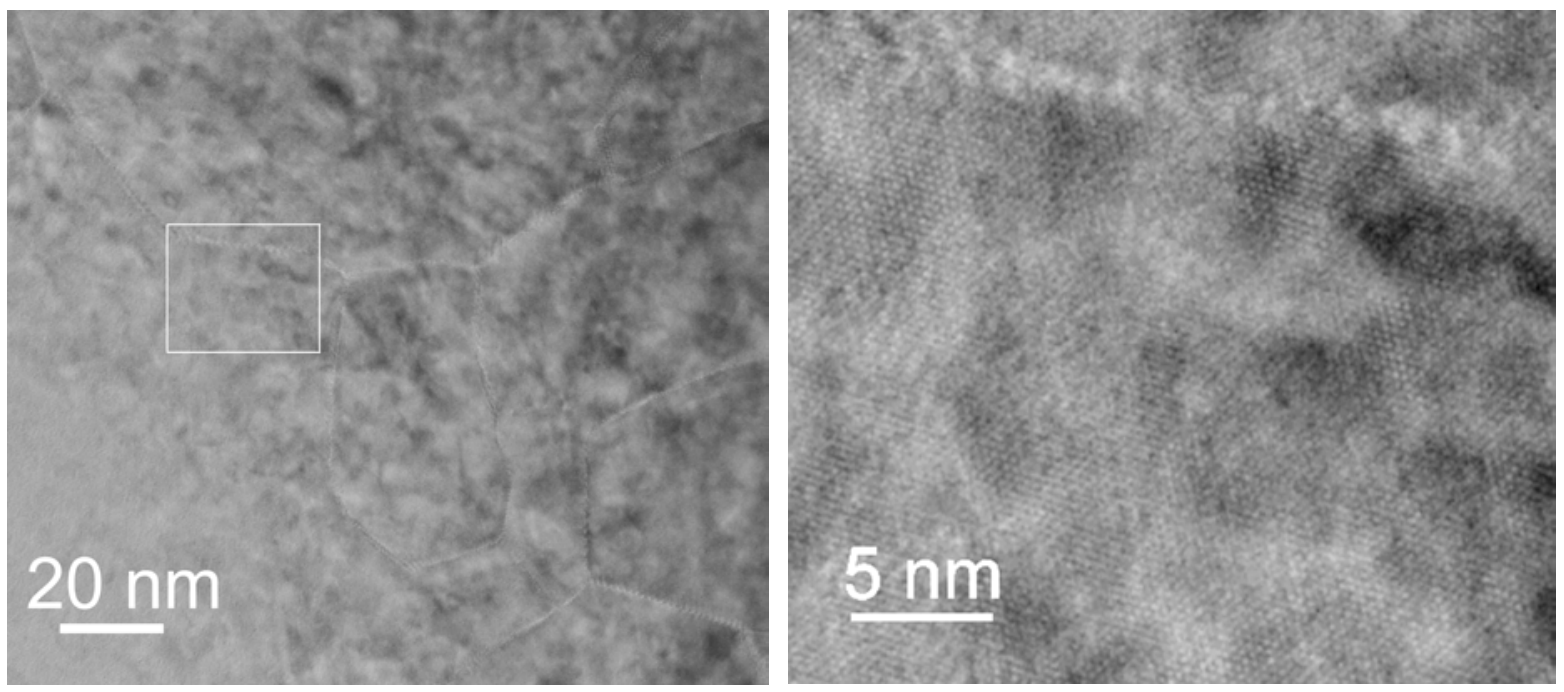

Figure 3 HREM image of a $\mathrm{Zn}_{1-\mathrm{x}} \mathrm{Mn}_{\mathrm{x}} \mathrm{O}(\mathrm{x}=0.01)$ thin film (left) and an enlarged image (right). 